\title{
SOBRE A RELAÇÃO HOMEM-TRABALHO NO CONTEXTO DA SOCIEDADE LÍQUIDO-MODERNA: REFLEXÕES A PARTIR DE ZYGMUNT BAUMAN
}

\author{
Rafael Bianchi Silva \\ Universidade Estadual de Londrina - UEL - Brasil \\ Jessica Pedrosa Mandelli \\ Centro Universitário Filadélfia - Unifil/Londrina - Brasil \\ Daniela Midori Taguchi Dias \\ Universidade Estadual de Maringá - PPI/UEM - Brasil
}

\section{Resumo}

Este trabalho tem como objetivo discutir sobre a relação homem-trabalho na sociedade líquidomoderna, conforme termo cunhado pelo sociólogo polonês Zygmunt Bauman. Observa-se que o trabalho na contemporaneidade assume um novo papel, com novas formatações, não sendo mais caracterizado pela estabilidade ou mesmo, visto como elemento central no projeto de vida da maior parte da população. Devido à instabilidade relacional, o vinculo entre homem, organização e trabalho configura-se como sendo de curto prazo. Nesse sentido, a flexibilização ganha espaço e com ela, a ampliação de trabalhos considerados como precários, além da forte presença de um discurso que preza pela valorização da subjetividade tomada a partir de um viés utilitário. Assim, o homem e o trabalho passam a serem tomados a partir de sua relação com a lógica de consumo. Os processos de gerenciamento também passam por mudanças de forma a ter no caos e na incerteza o fundamento de sua prática. Dessa forma, as organizações passam a incentivar a busca de autoconstrução como forma de enfrentamento a fluidez e efemeridade do trabalho. Conclui-se por fim, que o psicólogo precisa refletir sobre as novas demandas por ele recebidas vinculadas ao momento acima descrito para assim buscar formas de potencialização de ações singulares pelos sujeitos em diferentes contextos organizativos relativos ao trabalho.

Palavras-chaves: Psicologia do Trabalho, Contemporaneidade, Zygmunt Bauman

\section{Introdução}

A sociedade liquido-moderna, termo cunhado pelo sociólogo polonês Zygmunt Bauman, é o momento onde a fluidez e a flexibilidade atuam de maneira predominante, deixando para traz a lógica e preceitos de ordem e regulação da época anterior, 
a sólida, dando espaço ao incerto, e materializando-se enquanto sociedade de consumo e do gozo imediato

O objetivo deste artigo é discutir, a partir dos elementos debatidos pelo autor, quais os efeitos do modo de vida da sociedade líquido-moderna nas relações de trabalho e de que forma se apresentam os desafios para a Psicologia neste campo de atuação. Conforme discorreremos a seguir, na atualidade, o capital já não está mais relacionado exclusivamente com o trabalho, mas tem uma liberdade jamais sonhada antes, o capital tornou-se independente da duração e de qualquer união com o trabalho. Outrora, o capital era associado com máquinas pesadas, grandes equipes trabalhando em fabricas; hoje o capital está leve, segue apenas com bagagem de mão, notebook e celular.

\section{Relação Homem-Trabalho}

É possível observar ao longo da obra de Bauman a descrição de uma série de mudanças que vem ocorrendo na sociedade no que diz respeito ao mundo do trabalho. No tempo da modernidade sólida ou pesada, o trabalho possuía uma relação relativamente estável com o capital de forma a ambos possuírem um vínculo de dependência. O trabalhador necessitava de seu emprego, da mesma forma, que a empresa reconhecia a necessidade de mão-de-obra - ainda que explorável e descartável - para a manutenção da produção. Tal tipo de vinculação gerava uma série de conflitos internos às organizações de trabalho, mas que possuíam como base a necessidade de encontrar um lugar comum que pudesse manter ou retomar um tipo de ordem social interna à organização que propiciasse condições de trabalho.

O que é observado no contexto contemporâneo é um novo de tipo de relação que não pode mais ser identificada pela condição de uma pretensa busca de estabilidade. Conforme indica o autor,

Talvez o termo "remendar" capte melhor a nova natureza do trabalho separado do grande projeto de missão universalmente partilhada da humanidade e do não menos grandioso projeto de uma vocação para toda a vida. Despido de seus adereços escatológicos e arrancando de suas raízes metafísicas, o trabalho perdeu a centralidade que se lhe atribuía na galáxia dos valores dominantes na era da modernidade sólida e do capitalismo pesado. $O$ trabalho não pode mais oferecer o eixo seguro em torno do qual envolver e fixar autodefinições, identidades e projetos de vida. Nem pode ser concebido com facilidade como fundamento ético da sociedade, ou como eixo ético da vida individual (2001, p.160, grifo nosso). 
A citação acima nos indica as características centrais do lugar do trabalho no contexto da contemporaneidade. O primeiro ponto a destacar é a sua incapacidade de ser uma das bases para constituição do que chamamos de eu. Ao perder a condição de traço identitário, o trabalho não consegue mais forjar-se enquanto elemento central no projeto de vida da maior parte da população, o que gera efeitos nos processos de formação humana colocados em movimento na sociedade atual.

O segundo ponto, não menos importante, é a perda da centralidade. Bauman nos mostra que a formação para o trabalho dá lugar para a formação para consumo. Assim, há uma submissão do primeiro ao segundo. O trabalho passa a ser condição para o consumo, perdendo o estatuto de fim em si. Como consequência, tem-se a perda do sentido do trabalho enquanto motor da ação humana para fins de desenvolvimento e aprendizagens de novos conhecimentos e habilidades. Ele fica subjulgado a uma nova esfera de produção não de mercadorias, mas sim, de bens de consumo. Como bem afirma Bauman (2008a, p.185), “[...] o valor e o glamour do trabalho se medem hoje com parâmetros estabelecidos para a experiência do consumidor".

Aponta o autor que se trata de uma nova forma de modelagem do capital, muito mais flexível e fluído, mas que permanece ao fim, em íntima condição de dependência, não mais da capacidade de produzir objetos, mas sim, na potencialidade de escoá-los, dissipá-los, vende-los. Assim,

O capital é dependente, para sua competitividade, efetividade e rentabilidade, dos consumidores - e seus itinerários são guiados pela presença ou ausência de consumidores ou pelas chances de "produzir consumidores" - de gerar e alimentar a demanda com ideias em oferta. Ao planejar as viagens do capital e impulsionar seus deslocamentos, a presença da força de trabalho é, na melhor das hipóteses, uma consideração secundária (BAUMAN, 2008b, p.40).

O terceiro ponto a destacar diz respeito ao termo "remendo". A necessidade de remendar aponta para uma ruptura que não parece disposta a ser vencida. A quebra do sentido relacional do trabalho gera uma flexão no sentido interno do ato de trabalhar. Bauman (2001) aponta que o trabalho, assim como outras dimensões da sociedade de consumo, precisa ser prazeroso ao indivíduo, não sendo mais medido pelos seus efeitos vinculares seja com as organizações de trabalho, seja pela relação com os outros trabalhadores, seja no papel do trabalho para a manutenção e/ou transformação da sociedade. 
Em outras palavras, tem-se uma mudança no sentido político do trabalho que não mais está atrelado a uma definição de classe (como era possível observar até quase o final do século XX). O trabalhador passa a ser concebido em uma dimensão individual, desatrelado a uma esfera coletiva, seja ela a organização de trabalho (empresa) seja ao papel social do trabalho no contexto societário (identidade de trabalhador).

Tal processo de ruptura está intimamente relacionado com os valores que passam a ser disseminados pela estrutura social. Um dos principais elementos é o imperativo de lidar com um mundo em constante mudança. Não cabe mais a descrição de papéis rígidos a ser executados ao longo da vida produtiva ou mesmo o chamado vocacional tão demarcado em práticas psicológicas tradicionais movidas pela lógica da "pessoa certa para o lugar certo".

[...] "Flexibilidade" é o slogan do dia, e quando aplicado ao mercado de trabalho augura um fim do "emprego como o conhecemos" anunciando em seu lugar o advento do trabalho por contratos de curto prazo, ou sem contratos, posições sem cobertura previdenciária, mas com cláusulas "até nova ordem." A vida de trabalho está saturada de incertezas. (BAUMAN, 2001, p. 169).

A flexibilidade torna-se um dos pilares da sociedade líquido moderna, sendo uma das características necessárias aos indivíduos para sobreviverem à instabilidade do tempo presente. Quando observada no campo do trabalho "[...] ela anuncia empregos sem segurança, compromissos ou direitos, que oferecem apenas contratos a prazo fixo ou renováveis, demissão sem aviso prévio e nenhum direito à compensação [...]" (BAUMAN, 2001, p.185). Amplia-se a sensação de descartabilidade e a necessidade de construir meios para competir com o outro, em vista de uma realidade social no qual os postos de trabalho tornam-se cada vez mais escassos.

Quando o emprego do trabalho se tornou de curto prazo, tendo sido despojado das perspectivas firmes e portanto tornando episódico, e quando virtualmente todas as regras que dizem respeito ao jogo de promoções e demissões são sucateados ou tendem a ser alterados bem antes que o jogo termine, existem poucas chances de que a lealdade e o compromisso mútuos surjam e criem raízes (BAUMAN, 2008b, p.37)

Ainda sobre essa questão, afirma que "[...] ninguém pode, portanto, sentir-se insubstituível - nem os já demitidos nem os que ambicionam o emprego de demitir os outros. Mesmo a posição mais privilegiada pode acabar sendo apenas temporária e 'até disposição em 
contrário' na falta de segurança de longo prazo, a 'satisfação instantânea' parece uma estratégia razoável. [...]" (BAUMAN, 2001, p. 185).

Somada a essa condição, encontramos a ampliação do discurso do empreendedorismo e do "faça você mesmo" somada a uma espécie de solipsismo quanto às formas de desenvolvimento de tais capacidades. Cabe a cada um buscar meios de sobreviver na selva de pedra do mundo contemporâneo. Nessa direção, encontramos a explosão de cursos profissionalizantes de nível básico que ao mesmo tempo em que surgem como um caminho viável de inserção no mercado de trabalho também se mostram insuficientes em face às exigências subjetivas que emergem nesse campo.

Dessa forma, a relação homem-trabalho passa a estar vinculada à presença de discursos psicológicos que remetem ao desenvolvimento de habilidades pessoais e, principalmente, interpessoais. A Psicologia abastece a ciência administrativa de forma a embasar estratégias de formação de um novo perfil profissional capaz de suportar às pressões do contexto presente.

Assim, como característica das novas formas de trabalho, compreendidos como flexível, mais importante que a qualificação do trabalhador em uma determinada atividade, é a abertura deste para aceitar quaisquer desafios que a organização necessitar. Assim, vimos crescer uma imensidão de tarefas e características em uma só função, comumente descritas por títulos genéricos - como, por exemplo, auxiliar de produção e analista de negócios - com a exigência de entregas nada especializadas. Isso permite que a organização reduza tempo ocioso dos trabalhadores, utilizando-os em diversas atividades, contratando um profissional em lugar de dois ou três, otimizando recursos, reduzindo custos.

Dessa forma, coloca-se em marcha o processo de flexibilização acima indicado, que tem na polivalência um de seus pilares fundamentais. Se, na modernidade sólida, tínhamos a repetição de uma mesma atividade e somente esta, por longo tempo na divisão do trabalho, no contexto líquido-moderno, temos uma diversidade de atribuições, capazes de controlar a esteira produtiva ao custo do tempo, vida e desqualificação do trabalhador.

Cabe ao psicólogo, selecionar e treinar trabalhadores flexíveis, caracterizados como indivíduos proativos e resilientes, que suportem o trabalho sob pressão e assim, estejam prontos para desenvolver qualquer atividade que lhe for entregue, respondendo com presteza e entusiasmo às metas da organização.

Retoma-se aqui a tarefa de autoconstituição já apontada anteriormente. Como indica Bauman (2014, p.39), a tarefa central é fazer-se de si mesmo uma mercadoria vendável, aumentando o poder de atração do consumidor final, no caso as empresas. Dessa forma, 
observa-se que a Psicologia ocupa um lugar importante nesse processo já que ela principalmente através de estratégias de treinamento corporativo ou de cursos preparatórios (como o coaching, por exemplo), oferecerá “[...] 'as ferramentas', os instrumentos exigidos para o trabalho de 'autofabricação' individualmente executados [...]”.

Espera-se que através de tais procedimentos seja possível fugir do que Sennett (2006) chamou de fantasma da inutilidade. Através de uma série de capacitações que forneceria algum nível de mérito que pode ser caracterizado por alguma perícia na execução de determinada atividade, o trabalhador estaria potencializado a permanecer mais distante de torna-se inútil ao mercado de trabalho, ainda que não perdesse a condição de ser descartável e/ou, em situações específicas, supérfluo. Nesse sentido, construímos uma cultura na qual o fracasso tornou-se um tabu e, portanto, algo a ser evitado a todo custo:

O fracasso é o grande tabu moderno. A literatura popular está cheia de receitas de como vencer, mas em grande parte, calada sobre como enfrentar o fracasso. Aceitar o fracasso, dar-lhe uma forma e lugar na história de nossa vida, pode ser uma obsessão interior nossa, mas raras vezes a discutimos com os outros. [...] (SENNETT, 1999, p.135).

Bauman (2001) aponta que os principais afetados por essa nova política do trabalho são aqueles que se encontram na base da pirâmide social. São trabalhadores sem alta qualificação profissional e que tendem a atuação a partir de tarefas não específicas. $\mathrm{O}$ autor os define como "trabalhadores de rotina" que:

[...] Sabem que são dispensáveis, e por isso não vêem razões para aderir ou se comprometer com seu trabalho ou entrar numa associação mais durável com seus companheiros de trabalho. Para evitar frustração iminente, tendem a desconfiar de qualquer lealdade em relação ao local de trabalho e relutam em inscrever seus próprios planos de vida em um futuro projetado para a empresa. É uma reação natural à "flexibilidade" do mercado de trabalho, que, quando traduzida na experiência individual de vida, significa que a segurança de longo prazo é a última coisa que se aprende a associar ao trabalho que se realiza (p.175).

A problemática descrita acima nos direciona novamente para um novo sentido do termo "remendo". A relação duradoura entre trabalhador e organização de trabalho, marca do tempo da modernidade pesada, ficou para trás. A flexibilização trouxe também a necessidade de permanecer aberto a novas possibilidades. Manter as janelas abertas é uma das artes que o indivíduo contemporâneo precisa aprender a exercer. Afinal de contas, 
[...] No mundo do desemprego estrutural ninguém pode se sentir verdadeiramente seguro. Empregos seguros em empresas seguras parecem parte da nostalgia dos avós; nem há muitas habilidades e experiências que, uma vez adquiridas, garantam que o emprego será oferecido e, uma vez oferecido, será durável [...] (BAUMAN, 2001, p.178).

No contexto atual, no que tange os laços no contexto de trabalho, para a manutenção da dinâmica de reengenharia empresarial, eles necessitam tornar-se/manter-se frágeis. Nesse sentido, Sennett (1999) afirma que a perda de confiança é um dos desdobramentos da instabilidade disseminado pelo/no capital. Assim, diferentemente de laços fortes que demandam associações e vínculos de longo prazo, "[...] o distanciamento e a cooperatividade superficial são uma blindagem melhor para lidar com as atuais realidades que o comportamento baseado em valores de lealdade e serviço" (p.25).

Isso vem de encontro com a afirmação de Bauman (2001, p.171) ao descrever a relação entre trabalho, compromisso e lealdade:

Quando a utilização do trabalho se torna de curto prazo e precária, tendo sido ele despido de perspectivas firmes (e muito menos garantidas) e portanto tornado episódico, quando virtualmente todas as regras relativas ao jogo das promoções e demissões foram esgotadas ou tendem a ser alteradas antes que o jogo termine, há pouca chance de que a lealdade e o compromisso mútuos brotem e se enraízem. Ao contrário dos tempos de dependência mútua de longo prazo, não há quase estímulo para um interesse agudo, sério e crítico por conhecer os empreendimentos comuns e os arranjos a eles relacionados, que de qualquer forma seriam transitórios [...] (grifo nosso).

Todo esse processo vem a evidenciar o que autor descreve como sendo o trabalho na sociedade líquido-moderna e a relação entre capital-trabalhador. Neste caso a fluidez de ambos se justifica em função do que vem sendo aqui discutido.

[...] a presente versão 'liquefeita', 'fluida', dispersa, espalhada e desregulada da modernidade pode não implicar o divórcio e ruptura final da comunicação, mas anuncia o advento do capitalismo leve e flutuante, marcado pelo desengajamento e enfraquecimento dos laços que prendem o capital ao trabalho (BAUMAN, 2001, p. 171). 
Esse desengajamento, enfraquecimento dos laços, impulsiona o imediatismo no trabalho que tanto beneficiam a ideologia de resultados imediatos em detrimento de uma preocupação moral com o outro, ou seja, o ser e estar para o outro. Fazemos parte de um grupo de precariados, caracterizados pelo sofrimento individual (trazidos pelas incertezas da vida), falta de dinheiro para pagar as contas básicas, aliadas a mesquinharia dos salários e fragilidade dos empregos. Para diálogo com Leonidas Donskis, Bauman (2014, p.83) pontua que esses sofrimentos dividem, separam as pessoas, trazendo uma incerteza existencial humilhante, que tem como fonte a mistura de ignorância e incerteza.

Uma mudança mais seminal também se seguiu. Ao contrário do "proletariado" de outrora, o "precariado" abarca pessoas de todas as classes econômicas. Todos nós, ou pelo menos 99\% de nós [...], somos agora "precários": os que já foram tornados redundantes e os que temem que seus empregos não sobrevivam a próxima rodada de cortes ou "reestruturação"; os portadores de diplomas universitários procurando em vão empregos adequados a suas habilidades e ambições; os empregados permanentes que tremem diante da idéia de perder seus lares e as economias de suas vidas no próximo colapso da bolsa de valores; e muitíssimos outros, que tem sólidas razões para não confiar na segurança de sua posição na sociedade.

Vimos ao longo dessa seção que a relação entre homem e trabalho passa por um momento de instabilidade. Considerando que as organizações de trabalho ao mesmo tem em que sofrem os impactos desse processo também o fomentam através de suas práticas. Assim, se na modernidade sólida o papel dos supervisores, gerentes, apontadores, foi importante para o rígido controle dos tempos e movimentos, quais são as estratégias que vem sendo utilizadas por estes controladores/administradores na sociedade líquido-moderna? De que forma eles tem lidado com a dimensão subjetiva nas relações de trabalho?

A seguir, discutiremos algumas características no exercício de gerenciamento das pessoas e organizações na contemporaneidade.

\section{Para uma análise da dinâmica organizacional na modernidade líquido-moderna}

Conforme viemos discutindo, as relações de trabalho passaram por uma série de mudanças no contexto da contemporaneidade, que como bem explica Bauman (2012, p.36) - em diálogo com Ricardo Mazzeo - trata-se de uma "[...] cultura do desengajamento, da descontinuidade e do esquecimento [...]" (grifo do autor). Nesta seção, discutiremos em especial 
alguns elementos presentes nas organizações neste contexto indicado, principalmente no que tange à logica de gerenciamento.

De modo geral, diferente da modernidade pesada, as empresas contemporâneas tem investido atenção não apenas na capacidade técnica de seus empregados, mas em especial, na dimensão subjetiva. Conforme pontuam Bauman e May (2010, p.90), "as organizações têm, então, de se mostrar mais interadas na pessoa como um todo, em seu temperamento, seus atributos, disposições, habilidades, conhecimentos e motivações".

Isso se deve principalmente devido a uma nova lógica de entendimento acerca da formação humana que coloca em segundo plano a dimensão formal para eleger, enquanto caráter excepcional e diferencial, a experiência enquanto modo de produção de si. É nesse sentido que Bauman (2012, p.48) afirma:

[...] Os "recursos escassos" básicos de que é feito o capital e cuja posse e gerenciamento fornecem a principal fonte de riqueza e poder são hoje, na era pós-industrial, o conhecimento, a inventividade, a imaginação, a capacidade de pensar e a coragem de pensar diferente - qualidades que as universidades foram convocadas a criar, disseminar e instilar.

$\mathrm{O}$ autor aponta que tal processo tratou-se de uma necessidade em vista das mudanças derivadas da globalização do capital que gerou, por sua vez, aumento da competição derivada das condições de desemprego e do avanço de novas tecnologias. Dessa forma,

[...] Favorecendo a subjetividade, a jocosidade e a performance, as organizações da era da "economia da experiência" precisavam e desejavam proibir (e de fato proibiram) o planejamento de longo prazo e acumulação de méritos. Isso pode manter os residentes sempre ocupados e em movimento - na busca frenética de novas evidências de que continuam a ser bem-vindos (BAUMAN, 2013, p.63).

A partir do deslocamento do enfoque para a dimensão subjetiva, foi necessário implementar também novas formas de gerenciamento do trabalho que ultrapassassem o controle burocrático de funções e tarefas previamente determinadas. Para tanto, a ciência administrativa construiu um novo corpus teórico que não mais buscou a ordenação e previsibilidade da conduta. 
Em suma, a nova filosofia gerencial é a da desregulamentação abrangente: desmembrar os padrões de procedimento firmes e rígidos que a burocracia moderna procurou impor. Em vez de mapas, ela prefere calidoscópios, e o tempo pontilhista em vez do linear. Situa a intuição, o impulso e os estímulos do momento acima do planejamento e dos projetos meticulosos (BAUMAN, 2013, p.66, grifo nosso).

Sennett (2006) afirma que esse processo deriva de uma mudança de poder do gerente para o acionista. Ou seja, a lógica do lucro a qualquer coisa sendo modulada por um mercado que não possui relação direta com a realidade cotidiana das organizações de trabalho. Resultados vertiginosos em curto prazo ao invés de crescimento estável de longo prazo passam a ser o imperativo central. Somado a isso, o processo de desregulação do capital leva a possibilidade real de desmantelamento ou fusões corporativas que, por sua vez, retroalimentam o processo de desmontagem dos padrões organizacionais.

Assim, mais do que generais da ordem, os gerentes na sociedade contemporânea precisam saber lidar com o caos. Não apenas no sentido de prever as mudanças e antecipar-se a elas, como também incentivar dentro dinâmica organizacional vigente, nos trabalhadores, o desenvolvimento de habilidades para atuarem em estado constante de crises e viragens. Sobre a mudança de paradigma no processo de gestão, Sennett (2006, p.43-44) afirma que:

[...] a beleza institucional consistia em demonstrar sinais de mudança e flexibilidade internas, dando pinta de empresa dinâmica, ainda que tivesse funcionado perfeitamente bem na época da estabilidade [...] A estabilidade parecia sinal de fraqueza, indicando ao mercado que a empresa não era capaz de inovar, encontrar novas oportunidades ou gerir de alguma outra forma a mudança.

De forma sintética, conforme explica Bauman (2013) no mundo liquidomoderno, os gerentes já não norteiam mais suas práticas através de ações rígidas prescritas pela "ciência da administração", composta por regras sólidas, permanentes e estáveis. Ao invés disso, o discurso administrativo passa a mirar a subjetividade e os modos de conduta enquanto objeto de captura que passam a ser estimulados, não apenas no contexto organizacional, mas como elementos da própria vida do trabalho.

Como premissa a esse processo, entende-se que qualquer conhecimento está fadado a envelhecer e perder suas vantagens de forma muito rápida. Por essa razão, os gerentes atualmente embasam seu trabalho na liberdade e autonomia, buscando uma rede de 
oportunidades dinâmica, sendo agentes participativos no jogo da incerteza, onde o caos assume o antigo lugar da ordem.

O autor coloca que a estratégia utilizada na sociedade líquido-moderna é justamente a de "semear, espalhar, propagar e cultivar a ambiguidade, a obscuridade e a insegurança" (2014, p. 169). Afirma que a habilidade de valorizar o enxuto e punir notícias de expansão de equipes ou emprego, bem como a capacidade de desviar, evitar, fugir se necessário, são políticas de desengajamento e descomprometimento e sinais de saber e sucesso gerenciais.

A defesa de uma organização pautada pela mudança/desordem é fundamentada na ideia de que o caos também e sua volatilidade pode oferecer novas possibilidades de desenvolvimento as pessoas, valorizando habilidades antes desprezadas e reprimidas pelas organizações de trabalho.

Pode-se explicar o fenômeno dos gerentes que se afastam de seu antigo caso de amor pela ordem, pela rotina, pela ordem rotineira e pela rotina ordeira; em vez disso, se apaixonam pelo caos e a incerteza crônica, como um ajuste prudente (ou "racional") as condições do tipo de globalização hoje praticado, notável por menosprezar o potencial valor defensivo do espaço, ao ignorar toda e qualquer linha Maginot e demolir todo e qualquer Muro de Berlim (dos quais se costumava esperar que protegessem os Oasis da ordem da invasão da incerteza) [...] (BAUMAN, 2013, p.65).

Assim, as organizações atualmente são caracterizadas aparentemente por formas mais soltas, podendo sofrer mudanças radicais em curto prazo ou sem aviso prévio, sendo pautadas principalmente pela desorganização. Quanto mais fluida, melhor. Em suma, como explicam Bauman e May (2010) as organizações estão expostas às mudanças frenéticas e relutar a isso corresponderia a desvantagens corporativas. Sendo assim, faz-se necessário ter uma equipe de funcionários que sejam dinâmicos, ágeis, flexíveis e preparados às mudanças sejam elas derivadas do meio exterior à organização - ou seja, da dinâmica do mercado/capital - sejam internas - pela reengenharia ou redimensionamento organizacional. Além disso, espera-se que as interações não sejam mais homogêneas e estáveis, mas sim, heterogêneas e passíveis das instabilidades e tensões a elas inerentes.

Retoma-se neste ponto a necessidade de autogerenciamento em face da impossibilidade da organização determinar tais caminhos formativos. O desenvolvimento da capacidade de suportar a dinamicidade do mercado - atrelado às exigências imediatas do consumo - coloca no momento presente, tempo de oportunidade para ampliação de horizontes 
e obtenção de novas aprendizagens. Surge o que Bauman (2013) chama de "economia da experiência" na qual cada um é convocado, a partir de sua existência, entendida em uma dimensão individual, constituir-se como agente (da organização).

Tal processo é marcado em nosso tempo pelo que o autor chama de “destruição criativa”, ou seja, "[...] viver num estado de transformação permanente, autoredefinir-se perpetuamente tornando-se (ou pelo menos tentando se tornar) uma pessoa diferente daquela que tem sido ate então [...]" (BAUMAN, 2009, p.99, grifo do autor).

Porém, o desenvolvimento de tais capacidades traz um si alguns desdobramentos. O primeiro aponta para a necessidade de, por um lado, buscar o profissional adaptado às novas exigências organizativas e, por outro, caso esse possibilidade esteja dificultada, as organizações precisam buscar meios de precisam lançar bases para que seja possível desenvolver, estimular e manter tais capacidades criativas e canalizá-las aos fins produtivos.

Assim, pontos como estética e design das salas, utilização de programas de avaliação psicológica em processos de contratação (não mais pautados apenas pelas baterias psicométricas) que propiciem e estimulem a valorização e libertação da "inteligência emocional", instalações de recreação no contexto do trabalho, entre outros, passam a ser aspectos importantes nas organizações. Realiza-se uma série de operações que visa maior atenção às características subjetivas do trabalhador, esperando que todos os possíveis benefícios afetivos proporcionem ao empregado uma sensação de comunidade e identificação com a empresa.

"Identidade" e "comunidade" são dois termos que remetem a certa estabilidade subjetiva. A flexibilização identitária já apontada na seção anterior passa a ser valorizada também como elemento diferencial para o sucesso ou fracasso de um grupo de trabalho. Esse, inclusive, será constantemente incentivado, sendo a formação de equipes um dos pontos de avaliação das práticas organizacionais.

Dessa forma, ao mesmo tempo em que é incentivado o exercício de ser a si mesmo, como forma de potencializar formas de expressões possivelmente úteis ao contexto de trabalho, é formada uma nova categoria profissional, não mais derivada de classe ou função. $\mathrm{O}$ colaborador substitui o "funcionário" e o "trabalhador", de forma a deixar em segundo plano os métodos coercitivos, degradantes e exploratórios do trabalho em detrimento de um discurso includente do indivíduo no poder decisório da organização.

Nessa direção, tem-se o que Bauman (2014) afirma ser um dos elementos mais importantes da revolução organizativa da sociedade líquido-moderna. Os processos de 
vigilância do trabalho, que eram caracterizados pela incidência sobre o ambiente direto organizacional e sobre o corpo do trabalhador a partir de práticas de obediência e submissão direta ao gerente, passam a ser endereçados ao próprio indivíduo de forma que:

[...] o ônus da prova e da responsabilidade pelo resultado, foi transmitido pelos gerentes (como líderes de equipe e comandantes de unidade) para os ombros dos executantes individuais [...]. A servidão, com a vigilância do desempenho 24 horas por dia, sete dias por semana, está se tornando plena e verdadeiramente, para os subordinados, uma tarefa do tipo "faça vocês mesmo" [...] (p.61, grifo nosso).

Aceitar essa nova tarefa implica no reconhecimento de fazer parte de um grupo, com seus valores, práticas e objetivos. O estímulo a tomar a empresa como lugar central para o desenvolvimento implica em certo nível de engajamento e confiança, traços em crise no contexto da sociedade líquido-moderna. Isso nos leva a construção de uma ideia de pertencimento que remete ao termo comunidade que Bauman (2003) faz referência enquanto um pretenso paraíso que oferece níveis aceitáveis de segurança em troca de algum nível de autonomia.

Podemos afirmar, portanto, que esse tipo de dispositivo sedutor utilizado pelas organizações contemporâneo possui uma contradição de base: ao mesmo tempo em que fomenta a necessidade de liberdade e autonomia do trabalhador para autocriação e (auto)gerenciamento dos problemas inerentes ao trabalho, cria-se formas de regulação e controle mais sutis que não podem mais ser localizados com facilidade, como por exemplo, na pessoa de um agente de segurança ou mesmo em uma câmera de vigilância. Em nosso contexto de vida, cada um é livre o suficiente para decidir o nível e as formas de servidão a qual irá ser submetido e é sobre tal elemento que incidirá, por exemplo, as estratégias de marketing corporativo dentro das organizações: é necessário mostrar que vale a pena fazer parte dessa comunidade, dessa família que cuida e se preocupa com a qualidade/modo de vida seus colaboradores/trabalhadores.

Assim, em tempos de liquidez, na identificação e no amparo a esta comunidade de "iguais" sob a ingerência do caos, mas ainda assim voltada a execução de um fím último comum, o indivíduo sente-se em uma espécie de "porto seguro", ainda que a âncora que prenda o barco tenha se perdido ao longo do caminho. 
As mudanças organizacionais, portanto, não significam necessariamente maior controle do trabalhador em relação ao seu trabalho, mas sim, uma diferente forma de sequestro quanto à força produtiva, não mais restrita a ação motora, mas principalmente, ao campo subjetivo. Nesse sentido, não se mudou o vetor relativo ao controle organizacional, visto que as empresas seguem possuindo maior capacidade de exercer poder, o que significa dizer, determinar aquilo que é importante ou não a ser valorizado e executado, dentro do espaço organizativo, além dos métodos de como deve ser feito.

\section{Considerações Finais}

As análises realizadas no presente artigo abordaram aspectos sobre a relação homem-trabalho e posteriormente sobre a dinâmica organizacional na sociedade líquidomoderna a partir das análises realizadas por Zygmunt Bauman. Primeiramente, são levantados elementos importantes na relação homem-trabalho contemporânea, onde ao contrário da sociedade sólida, o trabalho já não possui relação estável com o capital.

Conforme mudanças na relação homem-trabalho, consequentemente houve modificações também na dinâmica organizacional atual, desencadeando assim uma reengenharia organizacional, onde gerenciamento assume nova posição e objetivos, a rede de possibilidades é valorizada, os membros da organização precisam ser ágeis, flexíveis e preparados para lidar com a mudança constante.

A organização hoje precisa estar apta a vivenciar o caos e a incerteza, a razão e os pressupostos administrativos cedem lugar à desregulamentação, por fim as organizações são plásticas e flexíveis.

Como o profissional de psicologia esta inserido nas organizações e seu trabalho é norteado e focado pela mediação entre empresa e colaboradores, a prática do mesmo consequentemente sofreu modificações; a planificação organizativa, característica do contexto da modernidade pesada, deu lugar para às demandas relativas às mudanças contínuas pelas quais as pessoas são submetidas no contexto do trabalho, traço esse derivado da instabilidade do capital.

Para além disso, o controle organizacional/institucional encontra-se mais sutil, sendo interiorizado pelos trabalhadores, não apenas no que tange às necessidades do campo de trabalho, mas principalmente, derivado do amplo poder de sedução colocado em marcha pelas empresas no contexto líquido-moderno. As exigências técnicas e estratégias de coerção física deram lugar às capacidades e imperativos subjetivos o que fornece aos 
profissionais psi amplo campo de análise no que diz respeito às formas de captura do indivíduo na rede organizativa.

Outro aspecto relevante, é que as empresas não estão mais focadas apenas ao aspecto profissional de seu colaborador, mas tentam conhecê-lo como um todo, habilidades, motivações, subjetividade, etc., e o profissional de psicologia tem papel fundamental nessa relação, pois possui instrumentos que são fundamentais para mapear tal interação.

Por fim, é importante destacar que estes elementos, ainda que sejam encontrados de forma disseminados no campo social, chega às organizações de forma não uniforme. Assim, encontramos demandas muito próximas àquelas preconizadas no velho capitalismo paralelas a discursos subjetivista e individualista. Nesse sentido, é importante também ao psicólogo refletir acerca de sua prática, qual o posicionamento a ele demandado e as possibilidades de construir ações que potencialize resistência e singularidade na rede institucional ao qual encontra-se inserido.

\title{
ABOUT THE RELATIONSHIP MEN-WORK IN THE LIQUID MODERN SOCIETY: REFLETIONS FROM ZYGMUNT BAUMAN
}

\begin{abstract}
This paper aims to discuss the relationship between man and work on liquid-modern society, as a term coined by the polish sociologist Zygmunt Bauman. It is observed that in contemporary work takes on a new role, with new formats. It's no longer characterized by stability or even it hasn't been seen as a central element in the life project of most of the population. Because of the relational instability, the bond between man and work organization is characterized as being short-term. In this sense, the flexibility becomes hegemonic and with it, the expansion of precarious work, besides the strong presence of a discourse that values the appreciation of subjectivity taken from a utility way. So the man and the work are to be taken from their relationship with the logic of consumption. Management processes also undergo changes in order to take into chaos and uncertainty the foundation of your practice. Thus, organizations start to encourage the pursuit of self-construction as a way of confrontation the fluidity and transience of work. We conclude that the psychologist needs to reflect on the new demands received in contemporary times so as to find ways of empowering the singular actions by subjects in different organizational contexts relating to work.
\end{abstract}

Keywords: Work Psychology; Contemporary; Zygmunt Bauman 


\section{LA RELACION HOMBRE -TRABAJO EN EL CONTEXTO DE LA SOCIEDAD LIQUIDO-MODERNA: REFLEXIONES DESDE ZYGMUNT BAUMAN}

\section{Resumen}

Este artículo tiene como objetivo discutir la relación entre el hombre y el trabajo en la sociedad líquido-moderno, como definido por el sociólogo polaco Zygmunt Bauman. Se observa que en trabajo en la contemporaneidad adquiere un nuevo papel, con nuevos formatos y ya no se caracteriza por la estabilidad o mismo visto como un elemento central en el proyecto de vida de la mayoría de la población. Debido a la inestabilidad relacional, el vínculo entre el hombre, la organización y el trabajo se caracteriza por ser de corto plazo. En este sentido, la flexibilidad gana espacio y, con ella, la expansión del trabajo considerados precario, además de la fuerte presencia de un discurso que valora el reconocimiento de la subjetividad tomada de un sesgo de utilidad. Así que el hombre y el trabajo deben ser tomados de su relación con la lógica del consumo. Procesos de gestión también sufren cambios teniendo en el caos y la incertidumbre base de su práctica. Por lo tanto, las organizaciones comienzan a incentivar la construcción de sí mismo como una manera de afrontamiento a la fluidez y lo efímero del trabajo. Se concluye finalmente que el psicólogo tiene que reflexionar sobre las nuevas demandas recibidas por él vinculada al momento que se ha descrito anteriormente para buscar la manera de empoderar a las acciones individuales de los sujetos en diferentes contextos de organización de trabajo.

Palavras-clabes: Psicologia del Trabajo, Contemporaneidad, Zygmunt Bauman

\section{Referências}

Bauman, Z. Modernidade Líquida. Rio de Janeiro: Zahar, 2001.

2003.

. Comunidade: a busca de segurança no mundo atual. Rio de Janeiro: Jorge Zahar,

La Sociedad Situada. Buenos Aires: Fondo de Cultura Economica, 2008a.

. A Sociedade Individualizada: vidas contadas e histórias vividas. Rio de Janeiro:

Zahar, 2008b.

. A Arte da Vida. Rio de Janeiro: Zahar, 2009.

. Sobre Educação e Juventude. Rio de Janeiro: Zahar, 2012.

. Danos Colaterais: desigualdades sociais numa era global. Rio de Janeiro: Zahar,

2013

. Vigilância Líquida. Rio de Janeiro: Zahar, 2014.

Bauman, Z.; May, T. Aprendendo a pensar com Sociologia. Rio de Janeiro: Zahar, 2010. 
Bauman, Z.; Donskis, L. Cegueira Moral: a perda da sensibilidade na modernidade líquida. Rio de Janeiro: Zahar, 2014.

SENNETT, Richard. A corrosão do caráter: as consequências pessoais do trabalho no novo capitalismo. Rio de Janeiro: Record, 1999.

A Cultura do Novo Capitalismo. Rio de Janeiro: Record, 2006.

Data de recebimento: 10/10/14

Data de aceite: $28 / 07 / 16$

\section{Sobre os autores:}

Rafael Bianchi Silva é Doutor em Educação (Unesp/Marília). Docente do Departamento de Psicologia Social de Institucional da Universidade Estadual de Londrina (UEL) e do Programa de Pós-Graduação em Psicologia da Universidade Estadual de Maringá (PPI/UEM). Endereço eletrônico: tibx211@yahoo.com.br

Jessica Pedrosa Mandelli é Graduada em Psicologia pela Unifil/Londrina. Endereço eletrônico: jessicamandelli@hotmail.com

Daniela Midori Taguchi Dias é Mestre em Psicologia pela Universidade Estadual de Maringá (PPI/UEM). Endereço eletrônico: danitaguchi@ gmail.co 